\title{
Diabetes and oral health
}

\author{
Kjersti Skjold Rønningen ${ }^{1}$ and Morten Enersen ${ }^{2}$ \\ 1) Pediatrisk forskningsinstitutt, Oslo Universitetssykehus, Rikshospitalet \\ 2) Institutt for oral biologi, Det odontologiske fakultet, Universitetet i Oslo
}

Correspondence: Kjersti Skjold Rønningen, Pediatrisk forskningsinstitutt, Oslo Universitetssykehus, Rikshospitalet, Postboks 4950 Nydalen, 0424 Oslo E-mail: kjersti.skjold.ronningen@rr-research.no/kjersti.skjold.ronningen@gmail.com Telephone: 23072796/91647840

\begin{abstract}
SUMMARY
Background: Diabetes describes a group of disorders characterized by elevated levels of glucose in the blood and abnormalities of carbohydrate, fat and protein metabolism. A number of oral diseases and disorders have been associated with diabetes, and periodontitis has been identified as a possible risk factor for poor metabolic control in subjects with diabetes.

Methods: This paper reviews the scientific literature to identify oral conditions that have been proposed and are known to be affected by diabetes. The literature has also been examined concerning periodontitis as a modifier of glycemic control.

Results: Although a number of oral disorders have been associated with diabetes, the data support the fact that periodontitis is a complication of diabetes. Patients with long-standing, poorly controlled diabetes are at risk of developing candidiasis, and the evidence indicates that periodontitis is a risk factor for poor glycemic control and the development of other clinical complications of diabetes.

Conclusions: Diabetes is an important health care problem. The evidence suggests that oral health care, specifically in relation to periodontal diseases, can have a significant, positive effect on the oral as well as general health of patients with diabetes mellitus.
\end{abstract}

\section{BACKGROUND}

\section{Variants of diabetes}

Diabetes is a syndrome of abnormal carbohydrate, fat and protein metabolism that results in acute and chronic complications due to the absolute or relative lack of insulin. There are different variants of diabetes (1): "Type 1 diabetes," which is an autoimmune disease destructing the insulin-producing cells and resulting in an absolute insulin deficiency; "Type 2 diabetes", which is the result of insulin resistance and an insulin secretory defect, "Gestational diabetes," a condition of abnormal glucose tolerance during pregnancy. Eightyfive to 90 percent of patients with diabetes have type 2 , and 5-10 percent have type 1 diabetes. The last group consists of "Other rare variants of diabetes"; MODY (Maturity Onset Diabetes in the Young) and endocrinopathies.

\section{Incidence and prevalence}

Diabetes develops in people of all ages, and the prevalence has increased dramatically worldwide over the past several decades. In Norway there has been close to a doubling in the incidence of type 1 diabetes during the last 30 years (2-5). However, neither for type 1 or type 2 diabetes good prevalence data exist for Norway. As body mass index (BMI) also increases in the Scandinavian countries, it is estimated that there will be twice as many with type 2 diabetes in the near future $(6,7)$.

\section{Monitoring of diabetes}

The primary goal of therapy is to improve well-being and quality of life by reducing symptoms of hyper- glycaemia and, thereafter, to reduce the risk of short term (e.g. ketoacidosis or hyperosmolar coma) and long term complications. For both type 1 and type 2 diabetes, the prevention of complications is achieved by improving glycemic control. For glycemic control, it is recommended that the haemoglobin glycosylation $\left(\mathrm{HbA}_{1 \mathrm{c}}\right)$ level should be maintained at less than 7.1 percent (normal levels are between 4.1\%-6.1\%). $\mathrm{HbA}_{1 \mathrm{c}}$ levels above 9 percent reflect poorly controlled diabetes and indicate the need for aggressive diabetic control since there is an associated increase in complication rates for both microvascular and macrovascular disease (8-10).

\section{Effects of increased blood glucose level}

A number of pathological mechanisms related to elevated levels of glucose in the blood have been defined, including the activation of the sorbitol pathway, the formation of advanced glycation end products (ACEs), the damaging effect of oxidative stress, and altered lipid metabolism. These mechanisms have been associated with classical clinical complications of diabetes such as retinopathy, nephropathy, neuropathy, macrovascular disease, and poor wound healing. In 1993, Löe proposed periodontal disease to be the sixth complication of diabetes (11). In 2008, Taylor and Borgnakke (12) identified periodontal diseases as a possible risk factor for poor metabolic control in people with diabetes. This bidirectional relationship between periodontal diseases and diabetes makes diabetes a disorder of importance to dentists and dental hygienists and to patients seen in the dental office (10). In this article the association of oral health and diabetes will be reviewed. 


\section{METHODS}

The review is based on the scientific aspects of the relationship between diabetes mellitus and oral diseases performed by search on PubMed (at the end of August 2011) without any ambitions to follow rules for a Cochrane review. The command "diabetes and oral health" gave 4450 hits. The command "diabetes and oral disease" gave 8605 hits. It was therefore decided to use reviews published after the year 2000. Search using "diabetes and oral health" gave 73 hits, and "diabetes and oral disease" 123 hits. Of these 196 papers 16 reviews were used. However, during the review process of this paper, some additional references have been added to the reference list.

\section{RESULTS AND DISCUSSION}

A number of oral disorders have been associated with diabetes. The association between diabetes and periodontal diseases has received the greatest attention in relation to oral health and disease $(12,13)$. However, Ship also claims that dental caries, salivary dysfunction, oral mucosal diseases, oral infections such as candidiasis, taste and other neurosensory disorders can be oral signs of diabetes (13).

There is clear evidence in the literature that diabetes increases the risk of gingivitis and periodontitis (10, 13). Already at young age, the prevalence and severity of gingival inflammation have been demonstrated to be more significant in subjects with diabetes. Furthermore, longitudinal studies have shown an increased risk of developing periodontitis in subjects with diabetes compared to healthy subjects. The glycemic control may be a modifying factor in the onset and progression of periodontal diseases in diabetes patients. However, the association is difficult to define conclusively, due to the heterogeneity in the diabetic population. But it seems clear that poor glycemic control of diabetes increases the risk of diabetic complications as well as periodontitis, and diabetes patients with excellent glycemic control will reduce the risk of diabetic complications and severe periodontitis $(14,15)$.

\section{Periodontal diseases}

Periodontal diseases are a group of pathological conditions of the supportive tissues of the teeth, generally accepted as polymicrobial infections, caused by a biofilm of mainly Gr-, anaerobic, bacterial species. The subgingivally located biofilm (beneath the "gum margin") will there interact intricately with the hosts immune system. The result is a release of a broad array of inflammatory cytokines, chemokines and other inflammatory mediators which gradually cause destruction of the supporting structures of the teeth and being modified by other host related factors like smoking, genetic variance and systemic diseases, among them diabetes $(11,12,16,17)$. Due to the chronic nature of periodontal diseases, and unless the progression has reached a stage which results in increased mobility, positional changes of teeth, chewing difficulties and/or esthetical problems, the patients usually take little notice of their "gum" conditions. In this respect it is very import that dentists do a proper periodontal examination of their adolescent and adult patients as part of a routine dental examination $(10,12,18)$. Worldwide periodontal diseases represent a serious oral health problem and may be a major cause of partial or total tooth loss in the affected individuals. The proportion of affected people may vary among geographically, ethnically and racially different populations as well as age groups $(10,17,19)$. In the United States, all forms of periodontitis affect about $75 \%$ of the adult population, but generally it is agreed that approximately $5-15 \%$ of any population suffers from the advanced forms, while moderate forms affect approximately $50 \%$ of the population at the age of $50(10,17)$. In Norway estimates of the prevalence of periodontal diseases are assumed to be about the same as in the United States (20). However, there is a lack of Norwegian epidemiological data in this field.

A carefully considered periodontal diagnosis is of major importance in the management of a patient's periodontal disease as the first step toward a treatment plan, active treatment and resolution. Establishment of infection control through mechanical removal of the bacterial deposits (scaling and root planing) from the exposed root surfaces of the affected teeth is the main goal of the systematic periodontal treatment. From early classification, plaque (biofilm)-induced periodontal diseases have generally been divided into two categories, gingivitis and periodontitis. Plaque-induced gingivitis is the presence of gingival inflammation without loss of connective tissue attachment and a reversible condition, while plaque-induced periodontitis is the presence of marginal inflammation at sites where the epithelial cells migrate apical and onto the exposed root surfaces creating irreversible attachment loss. On the contrary, "health" implies in this respect the absence of plaque-induced gingivitis and periodontitis $(14,21)$. "Periodontal health" can also be established after successful periodontal treatment and last for many years with regular professional maintenance care (22).

The last reclassification of periodontal diseases (1999) consists of eight main categories of conditions where, "chronic periodontitis" and "aggressive periodontitis", are the two most common forms differing from each other by the age of onset as well as rate of progression. The diagnoses are further divided with regard to localized and generalized forms describing variable clinical pictures within the same diagnosis $(21,23,24)$.

The concept of bacteria playing an important role in periodontal diseases has been established since the nineteen-fifties with the introduction of the nonspecific plaque hypothesis, when it was suggested that removal of all bacterial deposits on the teeth was essential for treatment. Later, from a vast number of microbiological studies it became evident that some 
bacterial species frequently occurred together in plaque samples from periodontitis. Gradually our knowledge increased and a number of specific periodontal pathogens could be identified as possible risk factors for progression of disease $(16,19)$. Based on epidemiological data of microbial samples from patients with "chronic periodontitis" Socransky and co-workers identified in 1998 the red complex bacteria; Porphyromonas gingivalis, Treponema denticola, and Tannerella forsythia as the primary risk bacteria for progression (25). These findings are supported by a number of other studies linking the bacterial species to be potential specific periodontal pathogens. In spite of immense research in this field for nearly half a century and recent enhancements in periodontal microbiology, we still are looking for better ways to predict disease progression. In the meantime, we have to rely on the poor diagnostic tools, clinical parameter recordings as periodontal pocket measurements and bleeding on probing. The use of x-ray examinations should always be part of a routine dental examination $(17,18)$.

Periodontal diseases are recognized and welldocumented complications of diabetes $(10,15,24)$. The evidence supporting this relationship is based on epidemiologic data and animal model studies that help explain the pathophysiology of periodontal disease as a complication of diabetes $(10,26)$. Data suggest that periodontal diseases also may increase the risk of experiencing poor metabolic control $(10,12,15)$.

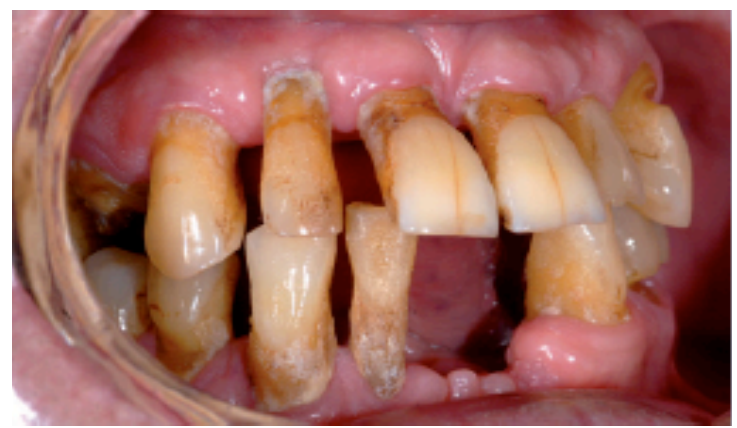

Figure 1. A patient with untreated periodontal disease.

\section{Diabetes as a risk factor for periodontal disease}

Many authors have described diabetes as a risk factor for periodontal disease. Hence, Mealey concluded that patients with diabetes had a tree-fold higher risk for periodontal disease compared with non-diabetic patients after controlling for age, sex, and other confounding factors (14). Possible mechanisms underlying the association between periodontal diseases and diabetes are currently under investigation and remain somewhat controversial (24). Some authors have described a possible common origin of the two diseases (27), whereas others consider that diabetes produces a hyper-inflammatory phenotype in certain cells due to the action of advanced glycation end products (AGEs)
(28-30). Genetic factors evidently play a major role in the susceptibility both to diabetes and periodontitis. However, the complex interactions in periodontal disease between host response mechanisms and the action of pathogenic microorganisms hamper clarification of the role of genetic factors (27). The role of the immune system in the etiopathogeny of diabetes and periodontal diseases is well documented (26,31). No doubt remains about the importance of the controlled release of cytokines and soluble factors that limit the noxious effects of both diseases. However, several findings also indicate that activation of inflammatory pathways may participate in the organ damage by diabetic complications. Other explanations of the interaction between the two diseases have been proposed based on their cell receptors (RAGEs) (28), which are present in certain diabetic patients, e.g. in endothelial or phagocytotic cells $(26,31,32)$. Hence, AGEs may be deposited on mononuclear or polymorphonuclear cells, inhibiting their chemotactic and phagocytic capacities, and permitting the advance of Gram-negative anaerobic bacteria, which would explain the higher prevalence and severity of periodontal disease in diabetic patients (28). According to this theory, AGE-stimulated macrophages and polymorphonuclear cells show a hyperresponse to the progression of bacterial biofilm, releasing a larger amount of cytokines and soluble mediators and producing a greater destruction of connective tissue in these patients.

Binding between ACEs and their receptors has also been observed in fibroblasts, which could have repercussions for collagen, the main component of periodontal tissue. Accordingly, interference with the collagen turnover could impair wound healing in patients with diabetes reducing the resistance of periodontal

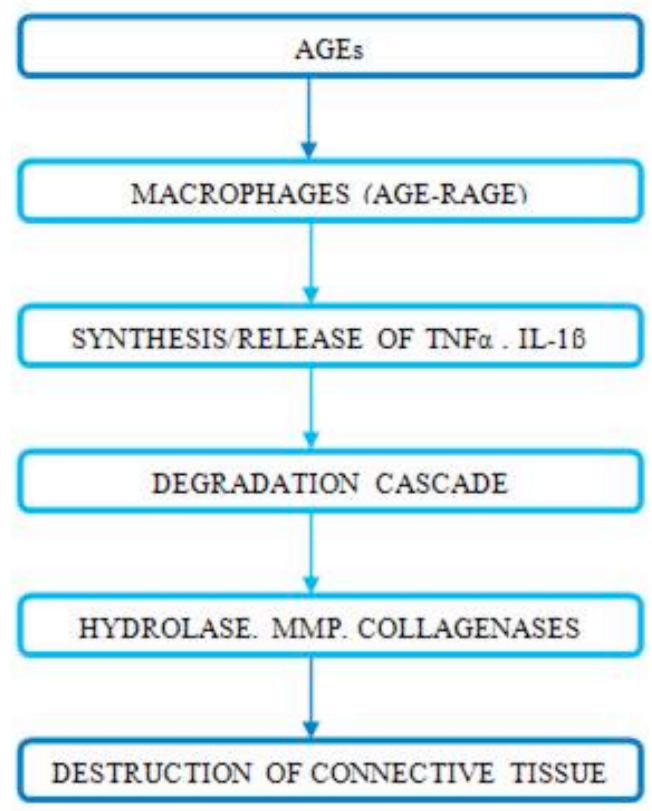

Figure 2. Model depicting how diabetes could contribute to the development of periodontal disease. 
tissues to bacterial attack (14). It has also been demonstrated that AGEs increase collagenase and other enzyme activity in connective tissue, thereby contributing to tissue destruction.

Matrix metalloproteinases (MMPs) are locally increased in periodontal disease-affected gingival pockets, and advanced periodontal disease has been associated with elevated salivary MMP levels. Furthermore, periodontal patients have also increased serum MMPs, which may be specific to infection with certain periodontal pathogens. It has been proposed that MMP-9 may link periodontal disease with cardiopathogenesis (33), which is also indicated from a number of other studies (34-37).

It has been shown in a biologically plausible manner, how the host defence capacity can be altered in diabetic and non-diabetic patients, suggesting that the increased periodontal disease risk in patients with diabetes derives from an AGE-generating immunologic disorder (14). In turn, periodontal pathogens cause the up-regulation of cytokines and tissue degrading enzymes, which also may have systemic consequences $(15,35,37,38)$.

\section{Periodontal disease as a risk factor for diabetes}

Recognition of the subgingival microbial biofilm has increased our understanding of the pathophysiology of periodontal disease. In these biofilms, bacteria are embedded in an extracellular matrix and adhere to one another and/or to the exposed root surfaces $(10,16,31$, 39). Bacterial adhesion is essential to establish the subgingival biofilm, and the pathogenic potential is determined by growth and maturation of the bacteria in question. These bacteria which are mainly Grnegative anaerobes constantly expel part of their cell structure components into the reticular space. The cell wall structures of these bacteria are of major importance in the pathogenesis of periodontal diseases. These are lipopolysaccharides and vesicles with protein content (proteases) that form part of the normal turnover of the cell wall of the microorganisms and activate the host response. The structure of the biofilm provides highly favourable conditions for the survival of the bacteria that form it, despite an intact host immune system. The virulence factors of these microorganisms are also responsible for triggering the sequence of pathogenic events in periodontal disease. Periodontal micro-organisms, in particular Porphyromonas gingivalis and Tannerella forsythia, have been found to increase MMP-9 in gingival crevicular fluid and serum $(16,33)$.

Excessive formation and accumulation of AGEs in tissues is the most common cause of diabetic complications. The binding of these molecules to neutrophils produces a hyperinflammatory state that amplifies the response to cytokines. These previously activated neutrophils also show a heightened response making contact with LPS of Gram-negative bacteria (e.g. P. gingivalis) in the subgingival biofilm, and the conse- quent triggering of the inflammatory cascade increases the destruction of periodontal connective tissue and the severity of diabetes $(36,37)$; further supporting the hypothesis of the systemic effects of periodontal diseases $(34,36,37)$.

\section{Periodontal treatment and glycemic control in diabetes}

Although the relationship between diabetes and periodontal disease is not questioned in the literature, the effect of the metabolic control of diabetes on periodontal disease and the effect of periodontal treatment on metabolic control in patients with diabetes remains controversial. In general, however, periodontal treatment is a high priority in patients for which periodontal disease may pose a health risk, and this includes patients with diabetes. Protocols have been described for the treatment and prevention of infections in patients with diabetes, mainly to control acute infection. However, according to current knowledge about the interactions of the subgingival microbiota with the immune system and the rise in serum concentrations of cytokines and other inflammatory mediators in periodontitis patients, treatment of these chronic infections should also be included in the protocols for treatment and prevention of infections in the diabetes patient group $(29,31,34)$.

The impact of periodontal diseases on the metabolic state in diabetes is significant. Diabetes patients with severe periodontitis have been reported to have increased risk of an altered glycemic control compared to diabetes subjects without periodontitis. Several metaanalyses comparing studies of the effect of periodontal treatment of type 1 and 2 diabetes patients have shown variable improvements in glycemic control, with a reduction of $\mathrm{HbA}_{1 \mathrm{c}}$ ranging from $0.40 \%$ to $0.66 \%$ following periodontal treatment (10). In another metaanalysis Janket et al. (39) reported a weighted average decrease of $\mathrm{HbA}_{1 \mathrm{c}}$ level of $0.66 \%$ for type 2 diabetic patients. Furthermore, periodontitis may also increase the risk for other diabetic complications such as cardiovascular, cerebrovascular and peripheral vascular events compared to diabetics without periodontitis. This is consistent with studies showing that the reduction of the systemic chronic inflammatory state of periodontal treatment normalizes the serum concentrations of cytokines and inflammatory mediators (10, $15,29,36,37)$, indicating that the outcome of periodontal treatment in well-controlled diabetes patients is similar to non-diabetic patients (40-42). The outcome of treatment in poorly controlled cases may be inferior $(15,35,38,43)$.

The most effective way to reduce the $\mathrm{HbA}_{1 \mathrm{c}}$ level is good blood glucose control for the reduction of diabetic late complications as well chronic inflammations such as periodontitis. Periodontal therapy should primarily consist of a systematic treatment by mechanical debridement without the use of antibiotics. In cases where the response to the conventional treatment is 
inferior or in refractive cases $(23,44,45)$, supplementary use of antibiotics should always be based on a microbial diagnosis and susceptibility testing of the microbiota (45). For those patients who received antibiotics as supplement to the mechanical periodontal treatment, Janket et al. (33) reported an average decrease in $\mathrm{HbA}_{1 \mathrm{c}}$ of $0.71 \%$.

\section{Dental caries}

The occurrence of dental caries in patients with diabetes has been studied, but no specific association has been identified (13). The relationship between dental caries and diabetes mellitus is complex. Children with type 1 diabetes are often given a diet that restrict their intake of carbohydrate-rich, cariogenic food, whereas adults with type 2 diabetes - which often is associated with obesity and intake of high-calorie and carbohydrate-rich food - can be expected to have a greater exposure to cariogenic foods. Furthermore, a reduction in salivary flow has been reported in people with diabetes and neuropathy (46), and diminished salivary flow is a risk factor for dental caries. The literature presents no consistent pattern regarding the relationship of dental caries and diabetes (23).

\section{Salivary function}

Dry mouth, or xerostomia, has been reported in people with diabetes. Salivary dysfunction, however, can be difficult to diagnose. Salivary flow may be affected by a variety of conditions, including the use of prescription medications and increasing age, and it appears to be affected by the degree of neuropathy and subjective feelings of mouth dryness that may accompany thirst. These variables are relevant for adults with diabetes. However, no definitive association of diabetes and reduced salivary flow has been identified $(23,46)$.

\section{Oral mucosal diseases and other oral infections}

A number of types of oral mucosal lesions, including lichen planus and recurrent aphthous stomatitis, have been reported in people with diabetes. Not all study results have shown this association, and these are relatively common disorders that often are observed in patients who do not have diabetes. In contrast, oral candidiasis has been a more consistent finding in patients with diabetes (47).

\section{Taste and other neurosensory disorders}

Taste disturbances have been reported in patients with diabetes (13), but not all investigators have observed this finding. Although patients with diabetes who receive haemodialysis have been reported to have altered taste (48), it is a complex symptom, and it may be related to salivary flow and changes in food intake associated with disease management. Other neurosensory disorders of the oral and perioral tissues, including burning mouth syndrome and dysphagia, have been reported in patients with diabetes (13). Prevalence data are not available. Retinopathy and peripheral neuropathy that affects patients' hands may severely limit a patient's ability to perform oral hygiene procedures (13).

\section{CONCLUSIONS}

Diabetes affects people of all ages, and its prevalence is rapidly increasing. Providing safe and effective oral medical care for patients with diabetes requires an understanding of the disease and familiarity with its oral manifestations. The goal of the therapy is to promote oral health in patients with diabetes, to help prevent and diagnose diabetes in dental patients receiving routine stomatological care and to enhance the quality of life for patients with this incurable disease.

\section{ACKNOWLEDGEMENT}

We thank professor Lise Lund Håheim and professor Ingar Olsen for longterm and stimulating collaboration on periodontitis and myocardial infarction.

\section{REFERENCES}

1. Alberti KGMM, Zimmet PZ. Definition, diagnosis, and classification of diabetes mellitus and its complications. Part 1: Diagnosis and classification of diabetes mellitus. Provisional report of a WHO consultation. Diabet Med 1998; 15: 539-553.

2. Joner G, Søvik O. Incidence, age at onset and seasonal variation of diabetes mellitus in Norwegian children, 1973-1977. Acta Paediatr Scand 1981; 70: 329-335.

3. Joner G, Stene LC, Søvik O; Norwegian Childhood Diabetes Study Group. Nationwide, prospective registration of type 1 diabetes in children aged <15 years in Norway 1989-1998: no increase but significant regional variation in incidence. Diabetes Care 2004; 27: 1618-1622.

4. Strøm H, Engeland A, Eriksen E, Sakshaug S, Rønning M. How many and who are receiving medication for diabetes mellitus? Tidsskr Nor Laegeforen 2006; 126: 768-770.

5. Patterson CC, Dahlquist GG, Gyürüs E, Green A, Soltész G; EURODIAB Study Group. Incidence trends for childhood type 1 diabetes in Europe during 1989-2003 and predicted new cases 2005-20: a multicentre prospective registration study. Lancet 2009; 373: 2027-2033.

6. Power C, Thomas C. Changes in BMI, duration of overweight and obesity, and glucose metabolism: 45 years of follow-up of a birth cohort. Diabetes Care 2011; 34: 1986-1991. 
7. Hertel JK, Johansson S, Sonestedt E, Jonsson A, Lie RT, Platou CG, et al. FTO, type 2 diabetes, and weight gain throughout adult life: a meta-analysis of 41,504 subjects from the Scandinavian HUNT, MDC, and MPP studies. Diabetes 2011; 60: 1637-1644.

8. Umpierre D, Ribeiro PA, Kramer CK. Physical activity advice only or structured exercise training and association with $\mathrm{HBA}_{1 \mathrm{c}}$ levels in type 2 diabetes: a systematic review and meta-analysis. $J$ Am Med Assoc 2011; 305: 1790-1799.

9. Dailey G. Overall mortality in diabetes mellitus: Where do we stand today? Diabetes Technol Ther 2011; 13 (suppl 1): 65-74.

10. Preshaw PM, Alba AL, Herrera D, Jepsen S, Konstantinidis A, Makrilakis K, Taylor R. Periodontitis and diabetes: a two-way relationship. Diabetologia. 2012; 55: 21-31.

11. Löe H. Periodontal disease: the sixth complication of diabetes mellitus. Diabetes Care 1993; 16: 329-334.

12. Taylor GW, Borgnakke WS. Periodontal disease: association with diabetes, glycemic control and complications. Oral Dis 2008; 14: 191-203.

13. Ship JA. Diabetes and oral health. An overview. J Am Dent Assoc 2003; 134: 1-10.

14. Mealey BL. Diabetes and periodontal disease: two sides of a coin. Compend Contin Educ Dent 2000; 21: 943946, 948, 950, passim; quiz 956.

15. Mealey BL, Oates TW. AAP-Commisioned review. Diabetes mellitus and periodontal diseases. J Periodontol 2006; 77: 1289-1302.

16. Socransky SS, Haffajee AD. Periodontal microbial ecology. Periodontol 2000 2005; 38: 135-187.

17. American Academy of Periodontology. Position Paper: Epidemiology of Periodontal Diseases. J Periodontol 2005; 76: 1406-1418.

18. Kidambi S, Patel SB. Diabetes mellitus: considerations for dentistry. J Am Dent Assoc 2008; 139: 8-18.

19. Socransky SS, Haffajee AD. The bacterial etiology of destructive periodontal disease: Current concepts. $J$ Periodontol 1992; 63: 322-31.

20. Evensen BJ, Holst D, Berg E, Hansen BF, Gjermo P. Systematisk periodontittbehandling i Norge. Tidsskr Nor Tannlegeforen 2006; 116: 622-626.

21. Armitage GC. Diagnosis and classification of periodontal diseases. Periodontol 2000 2004; 34: 9-21.

22. Axelsson P, Nystrøm B, Lindhe J. The long-term effect of a plaque control program on tooth mortality, caries and periodontal disease in adults. Results after 30 years maintenance. J Clin Periodontol 2004; 31: 749-757.

23. Taylor GW, Manz MC, Borgnakke WS. Diabetes, periodontal diseases, dental caries, and tooth loss: a review of the literature. Compend Contin Educ Dent 2004; 22: 179-192.

24. Soskolne WA. Epidemiological and clinical aspects of periodontal diseases in diabetics. Ann Periodontol 1998; 3: 3-12.

25. Socransky SS, Haffajee AD, Cugini MA, Smith C, Kent RL Jr. Microbial complexes in subgingival plaque. $J$ Clin Periodontol 1998; 25: 134-144.

26. Lalla E, Lamster IB, Feit M, et al. Blocade of RAGE suppresses periodontitis-associated bone loss in diabetic mice. J Clin Invest 2000; 105: 1117-1124.

27. Emrich LJ, Shlossman M, Genco RJ. Periodontal disease in non-insulin-dependent diabetes mellitus. $J$ Periodont 1991; 62: 123-131.

28. Grossi SG, Genco RJ. Periodental disease and diabetes mellitus: a two-way relationship. Ann Periodont 1998; 3: 3-12.

29. Pihlstrom BL. Periodontal risk assessment, diagnosis and treatment planning. Periodontol 2000 2001; 25: $37-$ 58.

30. Soskolne WA, Klinger A. The relationship between periodontal disease and diabetes: an overview. Ann Periodontol 2001; 6: 91-98.

31. Mealey BL, Rose LF. Diabetes mellitus and inflammatory periodontal diseases. Curr Opin Endocrinol 2008; 15: 135-141.

32. Lalla E, Lamster IB, Schmidt AM. Enhanced interaction of advanced glycation end products with their cellular receptor RAGE: implications for the pathogenesis of accelerated periodontal disease in diabetes. Ann Periodontol 1998; 3: 13-19.

33. Janket SJ, Wightman A, Baird AE, Van Dyke TE, Jones JA. Does periodontal treatment improve glycemic control in diabetic patients? A meta-analysis of intervention studies. J Dent Res 2005; 84: 1154-1159.

34. Kinane D, Bouchard P. Periodontal diseases and health: Consensus report of the Sixth European Workshop on Periodontology. J Clin Periodontol 2008; 35 (suppl 8): 333-337.

35. Serrano-Rios M, Corbaton A. Diabetes mellitus, heart failure and mortality. Med Clin (Barc) 2005; 125: 182183.

36. Buhlin K, Hultin M, Norderyd O, Persson L, Pockley AG, Rabe P, Klinge B, Gustafsson A. Risk factors for atherosclerosis in cases of severe periodontitis. J Clin Periodontol 2009; 36: 541-549. 
37. Buhlin K, Hultin M, Norderyd O, Persson L, Pockley AG, Pussinen PJ, et al. Periodontal treatment influences risk markers for atherosclerosis in patients with severe periodontitis. Atherosclerosis 2009; 206: 518-522.

38. Lindhe J. Clinical Periodontology and Implant Dentistry, 5th edn. 2008, Chapter 7.

39. Bascones A, Gamonal J, Gomez M, Silva A, Gonzalez MA. New knowledge of the pathogenesis of periodontal disease. Quintessence Int 2004; 35: 706-716.

40. Christgau M, Palitzsch KD, Schmalz G, Kreiner U, Frenzel S. Healing response to non-surgical periodontal therapy in patients with diabetes mellitus: clinical, microbiologica, and immunologic results. $J$ Clin Periodontol 1998; 25: 112-124.

41. Rodrigues DC, Taba MJ, Novaes AB, Souza SL, Grisi MF. Effect of non-surgical periodontal therapy on glycemic control in patients with type 2 diabetes mellitus. J Periodontol 2003; 74: 1361-1367.

42. Faria-Almeida R, Navarro A, Bascones A. Clinical and metabolic changes after conventional treatment of type 2 diabetic patients with chronic periodontitis. J Periodontol 2006; 77: 591-598.

43. Bascones-Martinez A, Matesanz-Perez P, Escribano-Bermejo M, Gonzalez-Moles M-A, Bascones-Ilundain J, Meurman J-H. Periodontal disease and diabetes - Review of the literature. Med Oral Patol Oral Cir Bucal 2011; 16: e722-799.

44. Adridge JP, Lester V, Watts TL, Collins A, Viberti G, Wilson RF. Single-blind studies of the effects of improved periodontal health on metabolic control in type 1 diabetes mellitus. J Clin Periodontol 1995; 22: 22712275.

45. Teles R, Haffajee AD, Socransky SS. Microbial goals of periodontal therapy. Periodontol 2000 2006; 42: 180-218.

46. Moore PA, Guggenheimer J, Etzel KR, Weyant RJ, Orchard T. Type 1 diabetes mellitus, xerostermia, and salivary flow rates. Oral Surg Oral Med Oral Pathol Oral Radiol Endod 2001; 92: 281-291.

47. Guggenheimer J, Moore PA, Rossie K, et al. Insulin-dependent diabetes mellitus and oral soft tissue pathologies, II: prevalence and characteristics of Candida and Candidal lesions. Oral Surg Oral Med Oral Pathol Oral Radiol Endod 2000; 89: 570-576.

48. Matsuo S, Nakamoto M, Nishihara G, et al. Impaired taste acuity in patients with diabetes mellitus on maintenance hemodialysis. Nephron Clin Pract 2003; 94: c46-c50. 